\title{
CONCEPÇÕES DE APRENDIZAGEM COM O COMPUTADOR EM ESTUDANTES UNIVERSITÁRIOS
}

\author{
Isabel Rebelo ${ }^{1}$ \\ António Duarte ${ }^{2}$
}

Resumo: Tendo como objectivo conhecer as representações dos estudantes sobre a aprendizagem mediada pelo computador, este estudo pretendeu testar a eventual replicação, no que toca à ideia do computador como meio de aprendizagem, das variantes da concepção de aprendizagem propostos pela perspectiva "fenomenográfica", assim como revelar concepções possivelmente novas. Este estudo baseou-se em entrevistas semi-estruturadas centradas em quatro dimensões de análise das concepções de aprendizagem com o computador: dimensão referencial (o que é a aprendizagem com o computador); processual (como se aprende com o computador); contextual (onde se aprende com o computador) e dimensão funcional (para que se aprende com o computador). Os resultados derivaram de uma análise de conteúdo das respostas e revelaram alguma correspondência entre as concepções de aprendizagem com o computador e as concepções de aprendizagem em geral, conhecidas da investigação fenomenográfica (i.e. a aprendizagem enquanto acumulação de informação, enquanto compreensão ou enquanto obtenção de classificações). Estas concepções comportam variantes que o estudo permitiu diferenciar e que replicam ou inovam o leque de concepções de aprendizagem conhecido. Para além disso emergiu uma concepção nova, que salienta a eficiência e organização envolvida na aprendizagem com o computador.

Palavras-chave: Aprendizagem Académica; Concepções de aprendizagem; Concepções de aprendizagem com o computador; Fenomenografia

Conceptions of computer mediated learning in University students (Abstract): This study had the goal of knowing about students' representations on computer mediated learning by testing the eventual replication, concerning the idea of the computer as a learning medium, of the variants of conceptions of learning proposed by "phenomenography". The study was based on semi-structured interviews centred on four dimensions of conceptions of learning with the computer: referen-

\footnotetext{
1 isabel.gomes.rebelo@gmail.com

2 amduarte@fp.ul.pt (Faculdade de Psicologia da Universidade de Lisboa) 
tial dimension (what is computer-based learning); procedural dimension (how does learning with computers occur); contextual dimension (where does learning with computers occur); functional dimension (what is the function of learning with computers). Students' answers were subjected to content analysis and results showed that conceptions of learning with computers match, to some extent, with the major general learning conceptions found by phenomenographic research (i.e. learning as cumulating information, as understanding or as making the grade). These conceptions vary in sub-conceptions that the study allowed to differentiate, and that replicate or innovate de range of known conceptions of learning. Besides, a new conception of learning emerged that emphasizes efficiency and organization involved in learning with computers.

Keywords: Academic Learning; Conceptions of Learning; Computer mediated learning; Phenomenography

\section{Introdução}

A fenomenografia constitui uma área de investigação que surgiu na Universidade de Gotemburgo, na Suécia, durante a década 70 do séc. XX, com os trabalhos de Ference Marton e Roger Säljö. Marton (1986) descreve a Fenomenografia como envolvendo um "(...) método de investigação para mapear qualitativamente as diferentes maneiras pelas quais as pessoas experienciam, conceptualizam, percebem ou compreendem vários aspectos dos fenómenos e do mundo ao seu redor." (Marton, 1986, p. 31). Neste sentido, desde o seu início, a fenomenografia interessou-se sobre a concepção de aprendizagem dos estudantes, atendendo ao impacto potencial dessa concepção no modo de aprendizagem por eles efectivamente utilizado. Dessa forma, tem vindo a procurar elucidar as variações daquela representação através de um método de análise qualitativa que envolve a questionação aberta sobre o sentido da aprendizagem, normalmente por entrevistas, seguidas de uma análise de conteúdo de respostas. As três dimensões da concepção de aprendizagem normalmente estudadas pela Fenomenografia são a dimensão referencial (i.e. o que é aprender); a dimensão processual (i.e. como se aprende) e a dimensão contextual (i.e. onde se aprende).

Atendendo à variação da representação de aprendizagem, os estudos fenomenográficos apontam para a existência de duas concepções básicas de aprendizagem: uma concepção quantitativa e uma concepção qualitativa. A concepção quantitativa de aprendizagem define esta enquanto actividade de recolha ou aquisição de informação e sua acumulação, por memorização. Em contraponto, a concepção qualitativa de aprendizagem defende esta como processo de compreensão e/ou construção de significados, do qual pode 
eventualmente resultar o desenvolvimento e a mudança pessoal. Assim, o princípio elementar que descrimina as duas concepções básicas é a noção de significado, ausente na representação quantitativa da aprendizagem. Deste modo, a concepção quantitativa é pautada por um "modelo aditivo", representando a aprendizagem como o juntar de algo a um conjunto de conhecimentos existentes que assim se limita a ser ampliado (i.e. o todo como a soma das partes). Por contraste, a concepção qualitativa implica um "modelo sistémico", representando o resultado da aprendizagem como uma eventual reorganização de significados existentes, no sentido da constituição de novo equilíbrios (Biggs \& Moore, 1993).

Nesta linha, as duas concepções podem ser perspectivadas hierarquicamente - podendo a concepção qualitativa ser tida como a mais "avançada", na medida em que engloba e expande a concepção quantitativa de aprendizagem (Marton \& Booth, 1997; Säljö, 1979, citado por Cliff, 1998). Por outro lado, enquanto que a concepção quantitativa é "suficiente" para dar conta da aprendizagem de conteúdos simples (e.g. factos e competências básicas) ela mostra-se deficitária na representação da aprendizagem de conteúdos de nível superior, sendo para esse efeito exigível uma concepção qualitativa de aprendizagem (Biggs \& Moore, 1993).

Em acréscimo, paralelamente a uma concepção quantitativa e qualitativa de aprendizagem, Biggs e Moore (1993) defendem a existência de uma concepção "institucional" de aprendizagem. De acordo com esta concepção, ocorre aprendizagem quando é reconhecido, pela escola, de que se alcançou um padrão de aprendizagem estabelecido e atestado por classificações. Assim, segundo uma concepção "institucional" de aprendizagem a prova de que esta ocorreu é assim o ter "passado" e a prova de que ocorreu uma "boa aprendizagem" é ter obtido "boas notas", implicando assim, uma conceitualização da aprendizagem em função da instituição escolar. Num estudo mais recente, Edmunds e Richardson (2009) identificaram ainda, em acréscimo à concepção quantitativa e qualitativa de aprendizagem (que denominaram Intake of Knowledge e Construction of Knowledge) uma terceira concepção designada de Use of Knowledge.

Por outro lado, as concepções quantitativas e qualitativas diferenciam-se, cada uma, em concepções mais específicas que se constituem como suas variantes, num sistema de concepções de aprendizagem desvendado por Marton e colaboradores (1993) que se apresenta como constante em diferentes contextos, tendo sido corroborado por vários estudos posteriores (e.g. Duarte, 2007). De acordo com este sistema, existem assim seis concepções específicas de aprendizagem: as três primeiras integram uma concepção quantitativa e as três últimas uma concepção qualitativa. A primeira concepção (de tipo quantitativo) apresenta a aprendizagem como aumento de conhecimento, sendo normalmente expressa por definições vagas ou abstrac- 
tas, que recorrem a sinónimos da palavra aprendizagem, ou que apresentam esta de forma indiferenciada como aumento de conhecimento. Neste caso a aprendizagem é tida como um processo de aquisição e armazenamento, por adição ao conhecimento já existente. A segunda concepção (de tipo quantitativo) define a aprendizagem como memorização e reprodução, sendo pautada por uma representação daquela enquanto retenção de informação a reproduzir subsequentemente. Neste caso, a aprendizagem é tida como alcançável através do processo de memorização por repetição. Para a terceira concepção (de tipo quantitativo) que vê a aprendizagem como aplicação, aquela é definida como um fenómeno de aquisição, armazenamento e utilização da informação a ser recuperada e utilizada posteriormente. Segundo esta concepção a utilização da informação aprendida pode igualmente envolver a sua adaptação. Em contraste com as concepções anteriores, a quarta concepção (de tipo qualitativo) vê a aprendizagem como compreensão, referindo-se a esta como entendimento de significados ou seja, como o desenvolver de uma representação sobre dados conteúdos. Segundo esta concepção existem várias formas pelas quais esta compreensão de significado se processa: por um olhar crítico sobre os conteúdos; por análise da relação entre partes dos conteúdos e pela relação destes com outras informações; por desenvolvimento de uma nova perspectiva; e por consciência de diferentes perspectivas. A quinta concepção (de tipo qualitativo) considera a aprendizagem como reinterpretação de conhecimento, vendo-a como uma mudança das noções pessoais e, eventualmente, como um conhecimento em diferentes perspectivas. Segundo esta concepção a reinterpretação pode ser processada de duas formas: por aumento do conhecimento, ou por generalização do que se aprende num domínio a outros domínios. Finalmente, a sexta concepção de aprendizagem (de tipo qualitativo) entende esta como mudança pessoal, salientando o papel da reinterpretação de conhecimento no desenvolvimento do aprendente. Nesta linha, a aprendizagem opera-se por estabelecimento de uma "reciprocidade" entre sujeito e objecto de conhecimento, através de uma mudança pessoal contínua ou através de uma percepção de si próprio como capaz de aprender (i.e. em controlo).

Investigação mais recente aponta para a possibilidade de existência de novas concepções de aprendizagem para além das seis concepções descritas por Marton e colaboradores (1993). Por exemplo, alguns estudos revelam que certos grupos apresentam uma concepção "intermédia" de aprendizagem, que parece associar a concepção quantitativa com a concepção qualitativa de aprendizagem, representando esta enquanto resultado da conjugação entre a memorização e a compreensão da informação (e.g. Dahlin e Watkins, 2000; Duarte, 2006). Por outro lado, investigações com estudantes não Ocidentais, revelaram indícios de uma possível representação sobre a aprendizagem que Cliff (1998) classificou de "comunitária" (communalist concep- 
tion) e cujo teor aponta para uma noção da aprendizagem enquanto "obrigação moral ou social" em relação a uma figura de autoridade, como Deus ou a comunidade.

Relação das concepções de aprendizagem com o processo e o produto da aprendizagem

Uma das principais razões da importância das concepções que os estudantes têm sobre a aprendizagem consiste na relação destas com o tipo de processo e produto da aprendizagem. $\mathrm{Na}$ realidade, existem indícios de que tanto as abordagens que os estudantes utilizam na aprendizagem (i.e. a sua motivação e as suas estratégias de aprendizagem) como os seus resultados na aprendizagem (i.e. o sucesso e a qualidade da aprendizagem) se relacionam com as suas representações sobre a aprendizagem. Especificamente, as concepções quantitativa, qualitativa e institucional parecem tender a associar-se, correspondentemente, a uma abordagem "de superfície", "de profundidade" e "de sucesso" à aprendizagem (e.g. Van Rossum \& Schenck, 1984). A abordagem de superfície à aprendizagem caracteriza-se pela conjugação entre uma motivação instrumental (i.e. estudo do mínimo, para evitar o insucesso) e uma estratégia de superfície (i.e. estudo baseado na memorização mecânica, conduzindo, geralmente, a piores resultados escolares e a produtos de aprendizagem de qualidade mais reduzida). Por seu lado a abordagem de profundidade conjuga uma motivação intrínseca para a aprendizagem (i.e. estudo pelo prazer na aprendizagem) com uma estratégia de profundidade (i.e. estudo baseado na compreensão), associando-se, normalmente a melhores classificações a produtos de maior qualidade. Finalmente, a abordagem de sucesso à aprendizagem integra uma motivação de realização (i.e. estudar para obter classificações elevadas) com uma estratégia de organização à aprendizagem (i.e. controlo do contexto da aprendizagem), associando-se igualmente a melhores classificações mas a produtos de aprendizagem de qualidade variável.

Numa revisão da relação de diferentes variáveis envolvidas na aprendizagem, Entwistle e Peterson (2004) apontam a concepção quantitativa de aprendizagem como correlativa de uma abordagem de superfície e externamente regulada à aprendizagem e a concepção qualitativa como relacionada com uma abordagem de profundidade e auto-regulada à aprendizagem.

A aprendizagem com o computador e a sua representação pelos estudantes

Embora o projecto de investigação original da fenomenografia consista na pesquisa das concepções da aprendizagem geral, estudos posteriores orientaram-se para uma análise mais específica das concepções que os estu- 
dantes têm da aprendizagem em tarefas particulares. É nesse sentido, que Säljö (1982, 1984) analisou as concepções de leitura, Hounsell (1984) estudou as concepções de composição escrita ou Rendeiro e Duarte (2007) investigaram as concepções de aprendizagem para a avaliação. Pela importância e actualidade da aprendizagem com as novas tecnologias, a representação dos estudantes sobre a aprendizagem com o computador merece uma atenção similar.

A utilização das TIC (i.e. Tecnologias da Informação e da Comunicação) em contexto educacional e do computador em particular parece revelar potencialidades interessantes para o melhoramento do sucesso e da qualidade da aprendizagem (e.g. Duarte, 2008). Antes de mais, porque essas tecnologias são naturalmente atractivas para os estudantes e, consequentemente, quando são utilizadas, tendem a promover um envolvimento mais activo na aprendizagem (Laurillard, 1994). Para tal também concorrerá a natureza interactiva da maior parte das aplicações informáticas, que permitem uma utilização personalizada do ambiente de aprendizagem e "reagem" de forma diferenciada às acções dos utilizadores (van den Brink et al., 2000). Considerando ainda que muita da informação disponibilizada por essas aplicações está estruturada no formato "hipermédia" (i.e. combinação do modo de estruturação não linear do texto escrito, em "hipertexto", com o modo de apresentação multisensorial, em registo "multimédia") considera-se que elas constituem um importante meio de modelação do conhecimento e amplificação da actividade cognitiva (Dias, 2000). No mesmo sentido, o computador constitui uma ferramenta com um enorme potencial na promoção de uma representação organizada do conhecimento. Jonassen (1996) sugere, por exemplo, a utilização de programas para a construção de mapas conceptuais e de bases de dados como forma de desenvolver estratégias de organização de informação. Para além disso, atendendo a que os computadores podem estar conectados em redes de comunicação, a sua utilização pode facilitar a interacção social no contexto de uma aprendizagem colaborativa (Duarte, 2000).

Mas será que, apesar deste potencial, o uso das novas tecnologias em contexto educacional melhora efectivamente a aprendizagem? Apesar do seu potencial em favorecer uma aprendizagem significativa as novas tecnologias também podem funcionar como recursos para manter, e até tornar mais eficiente, uma aprendizagem passiva (a estratégia de "copiar-colar" informação da Internet, na elaboração de trabalhos escritos, é um exemplo disto). A este propósito, Laurillard (1994) salienta a importância das condições onde as novas tecnologias são efectivamente utilizadas: o conhecimento anterior dos estudantes em relação ao assunto abordado; a preparação para a realização de um exercício; a abordagem adoptada pelos estudantes; a sua percepção da avaliação; a organização do ensino; e diversos factores logísticos (e.g. materiais, recursos, apoio). 
Possivelmente, o impacto da aprendizagem com o computador depende da interferência de inúmeras variáveis contextuais e pessoais (e.g. Gerjets $\&$ Hesse, 2004). Dentro destas últimas, a representação que os estudantes desenvolvem sobre este tipo de aprendizagem poderá ser uma das mais influentes. De que modo varia então esta representação? Será que de forma análoga à maneira como os estudantes representam a aprendizagem em geral? Será que em função de novas concepções? A investigação sobre o tema das representações da aprendizagem com o computador é relativamente escassa.

Mavers e colaboradores (2002) exploraram, numa perspectiva fenomenográfica, as representações mentais dos estudantes sobre as TIC. Para isso solicitaram e realizaram uma análise de mapas conceptuais, que representam visualmente, através de desenhos esquemáticos, as noções dos estudantes sobre os computadores. Demonstraram assim que os estudantes possuem representações qualitativamente diferentes sobre a informática no seu mundo, em torno de duas dimensões conceptuais: a primeira destas dimensões refere-se ao uso das novas tecnologias (i.e. computador e seus detalhes técnicos, jogos, TV, telemóvel, informação, comunicação, musica, imagens, ensino e formação, outros); a segunda dimensão reporta-se ao local de utilização dessas mesmas tecnologias (habitação pessoal, escola, emprego, bancos, comércio, transportes, hospitais, bibliotecas, universidades e outros lugares públicos ou privados).

Shuell e Farber (2001) questionaram estudantes universitários sobre a sua percepção e uso das tecnologias educativas. Puderam assim descriminar uma representação daquelas tecnologias como auxiliares da aprendizagem, como potenciadoras da motivação e como facilitadoras da compreensão.

Numa outra investigação, com estudantes universitários Chineses, Zhang e Huang (2006) identificaram três distintas concepções de E-learning, que descreveram como a metáfora da "sobremesa" (o E-learning como suplemento da aprendizagem face-a-face); a metáfora da "biblioteca itinerante" (como aprendizagem informal e auto-dirigida, baseada em recursos disponíveis em diferentes contextos); e a metáfora do "banquete" (como aprendizagem colaborativa baseada na comunidade).

Kirby e colaboradores (2002) detectaram, em estudantes do pós-secundário, diferentes concepções sobre o nível de aplicação das competências de utilização das tecnologias da informação. Neste estudo, ao contrário dos estudantes com uma abordagem de superfície à aprendizagem, aqueles com uma abordagem de profundidade concebem aplicações de nível mais elevado para aquelas competências.

Noutra investigação exploratória, com estudantes Europeus do ensino básico e secundário, van den Brink e colaboradores (2000) também investigaram, entre outras variáveis, as concepções de aprendizagem com o compu- 
tador. Estes autores concluíram que os estudantes podem representar a aprendizagem com o computador em termos: a) quantitativos (i.e. uso do computador como forma de adquirir e aplicar mais conhecimento sobre as matérias escolares); b) qualitativos (i.e. o computador como um meio facilitador da compreensão sobre as matérias); c) institucionais (i.e. o computador como meio de obter classificações). Esta variação indicia que o computador pode ser basicamente, representado pelos estudantes, como um recurso ou um meio de actualizar uma concepção de aprendizagem previamente estruturada. Ou seja, um recurso que pode aumentar a eficácia desse tipo de aprendizagem (i.e. como forma de "aumentar a motivação", "acelerar a aprendizagem" ou "reduzir a carga de informação"). Neste sentido, os autores deste estudo concluíram que as concepções da aprendizagem com o computador podem variar, numa primeira instância, entre uma concepção qualitativa e uma concepção quantitativa. Segundo a concepção quantitativa o uso do computador seria tido como forma de adquirir mais informação. Por outro lado, na concepção qualitativa o uso do computador é considerado como um modo de compreender e transformar conhecimento. Numa outra instância, em termos institucionais, o uso do computador seria ainda tido como meio de obter classificações. Insinuou-se assim uma replicação, no contexto das representações da aprendizagem com o computador, das concepções de aprendizagem em geral propostas pela perspectiva fenomenográfica. $\mathrm{Ou}$ seja, que as concepções dos estudantes em torno da aprendizagem com o computador estão contidas nas suas concepções da aprendizagem em geral (ou, pelo menos, que as primeiras não são significativamente distintas das segundas).

O estudo empírico que a seguir se apresenta, constitui um contributo para o conhecimento, ainda escasso, das concepções de aprendizagem com o computador. Pretendeu assim mapear esta concepção, através de uma avaliação qualitativa, em estudantes Universitários. Procurou, em particular, testar a possível replicação, no que diz respeito à noção do computador como meio de aprendizagem, dos diferentes tipos de concepção de aprendizagem propostos pela perspectiva "fenomenográfica", assim como detectar concepções eventualmente novas. Neste sentido, do enquadramento teórico anterior será especificamente retomado, no estudo empírico, a noção de que as representações da aprendizagem com o computador, tal como as concepções de aprendizagem em geral, variam num espectro diversificado (Mavers et al., 2002; Van den Brink et al., 2000; Zhang \& Huang, 2006). Será igualmente retomada a noção de que essa variação é concordante com a variação detectada pela investigação fenomenográfica na concepção de aprendizagem em geral, que diferencia esta como aquisição de conhecimento, compreensão ou obtenção de resultados escolares (Marton et al, 1993; van den Brink et al, 2000). 


\section{Método}

Foi utilizada uma abordagem qualitativa de recolha e tratamento de dados, inspirada na perspectiva fenomenográfica. A amostra foi constituída por 21 estudantes universitários de uma licenciatura em Ciências de Educação, 6 destes estudantes $(28.6 \%)$ frequentavam o $1^{\circ}$ ano de licenciatura, 3 $(14.3 \%)$ o $2^{\circ}$ ano, $5(23.8 \%)$ o $3^{\circ}$ ano e $7(33.3 \%)$ o $4^{\circ}$ ano. A razão da escolha de estudantes universitários foi a de que se pretendia uma amostra de participantes desenvolvidos do ponto de vista verbal (i.e. que pudessem responder sem problemas à entrevista) e com uma experiência significativa de utilização de uma aprendizagem mediada pelo computador. Efectivamente, todos estes estudantes tinham experiência de aprendizagem com o computador, utilizando-o na sua maioria $(76,2 \%)$ "muito frequentemente" 3 . Todos tinham tido frequência de disciplinas da área das Tecnologias Educativas. Dos 21 estudantes que compuseram a amostra, 14 (66.7\%) pertencem ao sexo feminino e $7(33.3 \%)$ pertencem ao sexo masculino. A idade destes estudantes varia entre os 18 e os 25 anos, com uma média de 20.9 anos e um desvio padrão de 1.67 , apresentando a maioria $(15-71,4 \%)$ idades compreendidas entre os 20 e os 22 anos. A amostra foi constituída de forma oportunista, em função de estudantes contactados ao acaso numa Universidade pública, não sendo representativa da população.

Com vista à recolha de dados que permitissem caracterizar as concepções dos estudantes sobre a aprendizagem com o computador procedeu-se à elaboração de um guião de entrevista. Este guião contém questões referentes a três dimensões normalmente estudadas pela perspectiva fenomenográfica: dimensão referencial (noção do que é aprendizagem com o computador); dimensão processual (noção de como se aprende com o computador); dimensão contextual (noção de onde se aprende com o computador). As primeiras três questões preparadas para a entrevista foram assim: "O que é a aprendizagem com o computador?"; "Como se aprende com o computador?"; “Onde se aprende com o computador?". O guião inclui também uma outra questão referente à dimensão funcional da concepção de aprendizagem (noção da função da aprendizagem com o computador): "Para que se aprende com o computador?". Seguiu-se um modelo de entrevista semi-estruturada, ou seja, em complementaridade com as questões previamente elaboradas foram colocadas outras perguntas, pensadas pelo entrevistador na altura da questionação, tendo em conta as necessidades do momento e os

3 Os participantes foram inquiridos quanto à frequência de utilização do computador, quantificando-a numa escala de 5 níveis (i.e. 1-nunca; 2-raramente; 3-algumas vezes; 4 frequentemente; 5-muito frequentemente) 
objectivos do estudo. As entrevistas, áudio gravadas com consentimento informado, foram realizadas nas instalações (i.e. salas de estudo) da Universidade frequentada pelos participantes e variaram entre cerca de $40 \mathrm{mns}$ a cerca de $60 \mathrm{mns}$.

A análise das respostas consistiu numa análise de conteúdo, que envolveu três momentos principais: 1) opção por um critério de segmentação das unidades a categorizar; 2) desenvolvimento de um sistema de categorias de análise; 3) testagem da confiança das categorias detectadas, por comparação entre juízes.

O critério de segmentação das unidades a categorizar foi o de "segmentação por unidades temáticas" (Flores, 1994), ou seja, todo o segmento de resposta que abordasse, pelo seu conteúdo, qualquer das dimensões focadas do fenómeno da aprendizagem (i.e. referencial, processual, contextual ou funcional) foi considerado como uma unidade a categorizar, por correspondência a uma das categorias da respectiva dimensão - o que equivale a dizer que a segmentação das unidades coincide com a sua categorização. Atendendo à crítica ao método fenomenográfico, de que este exclui os participantes dos seus depoimentos, ao separar e retirar frases soltas do contexto em que estas foram produzidas (Säljö, 1994) a categorização procurou ser sensível ao contexto global das respostas fornecidas, de acordo com a sugestão de Svensson (1989, citado por Eklund-Myrskog, 1998).

A segmentação foi efectuada independentemente por dois juízes, sendo posteriormente submetida à discussão conducente a uma segmentação consensual. Não foram consideradas respostas em que os participantes se referiam ao seu modo próprio de aprendizagem com o computador, ou seja quando respondiam às questões referindo-se especificamente à sua própria prática de aprendizagem pessoal com o computador e não, como pretendido, à sua representação abstracta desse tipo de aprendizagem.

O método utilizado (i.e. "intermédio") para categorizar as respostas correspondentes às dimensões referencial, processual e contextual foi diferente do método empregue para a categorização das respostas correspondentes à dimensão funcional (i.e. "indutivo"). Para a categorização das repostas correspondentes às dimensões referencial, processual e contextual foi utilizada uma aproximação intermédia entre o que se pode designar uma abordagem "dedutiva" e outra "indutiva" (Miles \& Huberman, 1994). Ou seja, partiu-se de um modelo teórico (i.e. o fenomenográfico) para analisar o fenómeno em estudo, "filtrando" os dados, sempre que possível, com base em categorias de análise pré-existente. Paralelamente, a análise foi efectuada mantendo a sensibilidade a concepções emergentes e não previstas teoricamente. Após vários loops de análise foi possível chegar a um sistema de categorias tido como estável, no que diz respeito às respostas consideradas. Mais especificamente, com base nos resultados documentados pela investi- 
gação fenomenográfica, começou por se construir uma primeira grelha de análise das concepções de aprendizagem para cada uma daquelas dimensões. Esta grelha teve como intuito uma análise inicial de $20 \%$ das respostas, com o objectivo de se verificar quais as categorias de cada dimensão que têm correspondência no contexto específico deste estudo, quais as categorias infirmadas e quais as emergentes. De seguida, foi elaborada uma segunda grelha com as categorias confirmadas e categorias emergentes. Esta segunda grelha foi depois utilizada numa segunda análise da totalidade das respostas. $\mathrm{O}$ procedimento de categorização envolveu duas fases. Uma primeira fase compreendeu a codificação de cada segmento de resposta na dimensão correspondente, em função do seu conteúdo tratar do significado, do processo ou do contexto do fenómeno da aprendizagem com o computador (dimensão referencial, processual e contextual). Numa segunda fase de categorização, cada segmento foi depois codificado na variante a que correspondia, considerando o conjunto de categorias de cada dimensão. Com base nos resultados desta segunda análise, foi apurado um sistema final de categorização de concepções de aprendizagem com o computador que se apresenta na secção dos resultados.

Para a dimensão funcional, cuja análise foi do tipo indutivo, foi sendo desenvolvida uma primeira grelha de descrição de concepções de aprendizagem com o computador. Esta grelha foi depois novamente aplicada a todas as respostas da dimensão funcional, tendo permitido apurar um único sistema de categorias, que se apresenta na secção dos resultados.

Todas as análises foram realizadas independentemente por duas juízas (a autora e outra investigadora, com experiência de investigação fenomenográfica). Em situações pontuais de dúvida sobre a forma de categorizar algumas respostas, recorreu-se ao autor, enquanto especialista no domínio da fenomenografia.

$\mathrm{Na}$ Tabela 1 é possível consultar os valores do acordo inter-juízes quanto às categorias de cada dimensão ${ }^{4}$.

Tabela 1: Acordo inter-juízes quanto às categorias de cada dimensão

\begin{tabular}{lcccc}
\hline & $\begin{array}{c}\text { Dimensão } \\
\text { Referencial }\end{array}$ & $\begin{array}{c}\text { Dimensão } \\
\text { Processual }\end{array}$ & $\begin{array}{c}\text { Dimensão } \\
\text { Contextual }\end{array}$ & $\begin{array}{c}\text { Dimensão } \\
\text { Funcional }\end{array}$ \\
\hline $\begin{array}{l}\text { Coeficiente de } \\
\text { acordo }\end{array}$ & $84,3 \%$ & $80,5 \%$ & $90,7 \%$ & $83,8 \%$ \\
\hline
\end{tabular}

${ }^{4}$ Os cálculos foram baseados na fórmula sugerida por Bakeman e Gottman (1986): PA = (NA/ (NA+ ND)) 100 - onde "PA" corresponde à percentagem de acordo; "NA" à frequência dos acordos e "ND" à frequência dos desacordos. 


\section{Resultados}

Na generalidade, a análise das repostas às entrevistas permitiu constatar, no domínio das concepções de aprendizagem com o computador, a replicação das principais concepções de aprendizagem em geral, normalmente identificadas pela fenomenografia. Ou seja, registou-se a presença de uma concepção quantitativa (i.e. aprendizagem com o computador enquanto acumulação de informação, por memorização) e de uma concepção qualitativa (i.e. aprendizagem com o computador enquanto processo de compreensão e/ou transformação do conhecimento, que pode assim resultar no desenvolvimento pessoal). Para além disso, registou-se também aqui a designada concepção institucional, sugerida por Biggs e Moore (1993), que aqui define a aprendizagem com o computador enquanto obtenção de classificações académicas. Finalmente, parece ter emergido uma concepção nova - designada de organizacional - que se compreende em função do tipo de aprendizagem baseada na informática aqui considerada, e que salienta a componente de eficiência e organização da informação envolvida nessa aprendizagem.

Como é possível verificar na Tabela 2, que sintetiza o sentido destas concepções principais, cada uma delas ocorre irregularmente nas quatro dimensões de questionação consideradas.

Complementarmente, cada uma das principais concepções de aprendizagem com o computador exprime-se de forma diferenciada, através de variantes distintas, em cada uma das dimensões consideradas. Vejamos especificamente, e em maior detalhe, a natureza dessa variação.

\section{Dimensão Referencial - O que é a aprendizagem com o computador}

No que diz respeito a esta dimensão da concepção de aprendizagem com o computador a concepção quantitativa de aprendizagem expressa-se de três formas. Duas delas têm correspondência com concepções de aprendizagem em geral já identificadas: a aprendizagem com o computador enquanto "aquisição de informação" (i.e. aprender com o computador é adquirir novos conhecimentos) ou enquanto "memorização de informação", (i.e. aprender com o computador é memorizar informação). A terceira concepção quantitativa traduz uma noção emergente da aprendizagem com o computador enquanto acto de repetição de um procedimento. Com base nesta evidência conceituou-se uma concepção nova a que chamámos de "repetição".

Também no que toca à dimensão referencial, a concepção qualitativa surge aqui através da ideia da aprendizagem com o computador enquanto "compreensão" (i.e. aprender com computador é abstrair o significado dos conteúdos de aprendizagem) que replica uma noção já identificada na área da concepção de aprendizagem em geral. A nova concepção organizacional de aprendizagem encontra-se aqui representada numa noção que reflecte a 
aprendizagem com o computador como meio de processar a informação. Designámos esta concepção de "manipulação de informação".

Tabela 2: Principais concepções de aprendizagem com o computador

\begin{tabular}{|c|c|c|c|c|}
\hline Dimensões & $\begin{array}{l}\text { Concepção } \\
\text { Quantitativa }\end{array}$ & $\begin{array}{l}\text { Concepção } \\
\text { Qualitativa }\end{array}$ & $\begin{array}{c}\text { Concepção } \\
\text { Organizacional }\end{array}$ & $\begin{array}{c}\text { Concepção } \\
\text { Institucional }\end{array}$ \\
\hline $\begin{array}{l}\text { Referencial } \\
\text { Natureza da } \\
\text { aprendizagem } \\
\text { com o compu- } \\
\text { tador }\end{array}$ & $\begin{array}{l}\text { aquisição de } \\
\text { informação, } \\
\text { memorização, } \\
\text { repetição de } \\
\text { procedimentos }\end{array}$ & compreensão & $\begin{array}{l}\text { manipulação } \\
\text { de informação }\end{array}$ & $\begin{array}{l}\text { obtenção de } \\
\text { classificações }\end{array}$ \\
\hline $\begin{array}{l}\text { Processual } \\
\text { Processo de } \\
\text { aprendizagem } \\
\text { com o compu- } \\
\text { tador }\end{array}$ & $\begin{array}{l}\text { aplicando, } \\
\text { imitando, } \\
\text { praticando, } \\
\text { automatizando }\end{array}$ & $\begin{array}{l}\text { interagindo, } \\
\text { compreendendo, } \\
\text { modificando-se }\end{array}$ & - & - \\
\hline $\begin{array}{l}\text { Contextual } \\
\text { Contexto da } \\
\text { aprendizagem } \\
\text { com o compu- } \\
\text { tador }\end{array}$ & $\begin{array}{l}\text { a escola, } \\
\text { a habitação, } \\
\text { o emprego }\end{array}$ & o mundo & - & - \\
\hline $\begin{array}{l}\text { Funcional } \\
\text { Função da } \\
\text { aprendizagem } \\
\text { com o compu- } \\
\text { tador }\end{array}$ & $\begin{array}{l}\text { aquisição de } \\
\text { informação }\end{array}$ & $\begin{array}{l}\text { diversificação, } \\
\text { comunicação, } \\
\text { transferência, } \\
\text { facilitação, } \\
\text { construção, } \\
\text { autonomia, } \\
\text { motivação }\end{array}$ & $\begin{array}{l}\text { acessibilidade, } \\
\text { comodidade, } \\
\text { rentabilização, } \\
\text { portabilidade, } \\
\text { aprendizagem } \\
\text { à distância }\end{array}$ & - \\
\hline
\end{tabular}

Registou-se, por fim, a presença de uma noção análoga à concepção "institucional" e que neste caso corresponde à ideia que a aprendizagem com o computador consiste numa forma de obter classificações académicas.

O sistema de descrição das concepções de aprendizagem com o computador na dimensão referencial pode ser consultado na Tabela 3.

\section{Dimensão Processual - Como se aprende com o computador}

A nível desta dimensão a concepção quantitativa de aprendizagem parece exprimir-se aqui através de quatro noções distintas, assemelhando-se apenas uma delas à concepção de aprendizagem como um processo de apli- 
cação de conhecimento e que é normalmente identificada pela fenomenografia. Trata-se de uma noção (com três variantes) que defende que a aprendizagem com o computador se faz utilizando informação adquirida modificando-a, exploratoriamente ou por ensaio e erro. Designámos esta concepção de "aplicando".

Tabela 3: Dimensão referencial (R) - "O que é a aprendizagem com o computador"

\begin{tabular}{|c|c|c|}
\hline Concepção & Definição & Resposta ilustrativa \\
\hline $\begin{array}{l}\text { R1. Aquisição de } \\
\text { informação }\end{array}$ & $\begin{array}{l}\text { Aprender com o computa- } \\
\text { dor é aumentar os conhe- } \\
\text { cimentos pessoais }\end{array}$ & $\begin{array}{l}\text { "(...) armazenar informação } \\
\text { mas com a ajuda do computa- } \\
\text { dor." }\end{array}$ \\
\hline $\begin{array}{l}\text { R2.Memorização } \\
\text { de } \\
\text { informação }\end{array}$ & $\begin{array}{l}\text { Aprender com o computa- } \\
\text { dor é memorizar informa- } \\
\text { ção }\end{array}$ & $\begin{array}{l}\text { "(...) no momento em que ele } \\
\text { capta informação pertinente há } \\
\text { aprendizagem, porque é atra- } \\
\text { vés da retenção da informação } \\
(. . .) "\end{array}$ \\
\hline R3. Repetição & $\begin{array}{l}\text { Aprender com o computa- } \\
\text { dor é repetir um procedi- } \\
\text { mento }\end{array}$ & $\begin{array}{l}\text { "(...) as pessoas manipulam o } \\
\text { computador }(. . .) \text { e }(. . .) \text { têm } \\
\text { tendência a repetir esse mesmo } \\
\text { comportamento." }\end{array}$ \\
\hline $\begin{array}{l}\text { R4. Manipulação } \\
\text { de informação }\end{array}$ & $\begin{array}{l}\text { Aprender com o computa- } \\
\text { dor é processar informação }\end{array}$ & $\begin{array}{l}\text { "(...) seleccionar informação, } \\
\text { produzir informação, organizar } \\
\text { informação, categorizar infor- } \\
\text { mação e depois organizá-la." }\end{array}$ \\
\hline R5. Compreensão & $\begin{array}{l}\text { Aprender com o computa- } \\
\text { dor é abstrair o significado } \\
\text { dos conteúdos de aprendi- } \\
\text { zagem }\end{array}$ & $\begin{array}{l}\text { "(...) no momento em que o } \\
\text { sujeito apreende ou assimila } \\
\text { algo de novo, para ele que seja } \\
\text { importante." }\end{array}$ \\
\hline $\begin{array}{l}\text { R6. Institucionali- } \\
\text { zação }\end{array}$ & $\begin{array}{l}\text { Aprender com o computa- } \\
\text { dor é obter boas classifica- } \\
\text { ções }\end{array}$ & $\begin{array}{l}\text { "(...) as aprendizagens que nós } \\
\text { adquirimos através do compu- } \\
\text { tador são sobretudo (...) técni- } \\
\text { cas de sobrevivência para nós } \\
\text { termos boas notas nos traba- } \\
\text { lhos }(\ldots) "\end{array}$ \\
\hline
\end{tabular}

As restantes noções quantitativas do processo de aprendizagem com o computador parecem ser concepções emergentes, não encontrando correspondentes nos sistemas fenomenográficos conhecidos. Trata-se de uma concepção a que chamámos "imitando", por implicar a aprendizagem com o computador como processo de observação e imitação; de outra designada de "praticando", que reflecte a aprendizagem com o computador pela prática; e de uma concepção denominada de "automatizando", por implicar a aprendi- 
zagem com o computador como um processo de aplicação mecânica de um procedimento rígido.

Ainda para a dimensão processual, a concepção qualitativa de aprendizagem exprimiu-se aqui através de três noções distintas. Duas destas noções parecem replicar concepções conhecidas da aprendizagem em geral pela compreensão e pela mudança pessoal. A terceira noção consiste num conceito que não tem paralelo nos sistemas fenomenográficos, por sugerir que a aprendizagem por computador se faz por Interacção: interacção entre o aprendente e o computador; entre pares, numa insinuação da aprendizagem colaborativa; e entre aluno e professor. Denominámos esta concepção de "interagindo".

O sistema de descrição das concepções de aprendizagem com o computador na dimensão processual pode ser consultado na Tabela 4 .

Tabela 4: Dimensão processual (P) - "Como se aprende com o computador"

\begin{tabular}{|c|c|c|}
\hline Concepção & Definição & Resposta ilustrativa \\
\hline P1. Imitando & $\begin{array}{l}\text { Aprende-se com o com- } \\
\text { putador observando e } \\
\text { imitando (por aprendiza- } \\
\text { gem social) }\end{array}$ & $\begin{array}{l}\text { " }(\ldots) \text { ver as pessoas a } \\
\text { mexer no computador } \\
(\ldots) \text { tomar os mesmos } \\
\text { gestos por imitação." }\end{array}$ \\
\hline P2. Praticando & $\begin{array}{l}\text { Aprende-se com o com- } \\
\text { putador praticando }\end{array}$ & $\begin{array}{l}\text { "(...) praticando todas } \\
\text { as coisas que vão fazen- } \\
\text { do no computador." }\end{array}$ \\
\hline \multirow[t]{3}{*}{ P3. Aplicando } & $\begin{array}{l}\text { Versão a): aprende-se } \\
\text { com o computador modi- } \\
\text { ficando a informação } \\
\text { armazenada de modo a } \\
\text { poder utilizá-la }\end{array}$ & $\begin{array}{l}\text { “(...) reformular algo, } \\
\text { que se calhar }(\ldots) \text { já } \\
\text { sabia fazer ou já sabia } \\
\text { representar }(\ldots) \text { ". }\end{array}$ \\
\hline & $\begin{array}{l}\text { Versão b): aprende-se } \\
\text { com o computador de } \\
\text { forma exploratória }\end{array}$ & $\begin{array}{l}\text { "(...) tentando, experi- } \\
\text { mentando e aventuran- } \\
\text { do" }\end{array}$ \\
\hline & $\begin{array}{l}\text { Versão c): aprende-se } \\
\text { com o computador por } \\
\text { ensaio e erro }\end{array}$ & $\begin{array}{l}\text { " (...) tentando, erran- } \\
\text { do." }\end{array}$ \\
\hline P4. Automatizando & $\begin{array}{l}\text { Aprende-se com o com- } \\
\text { putador por aplicação } \\
\text { mecânica de um procedi- } \\
\text { mento rígido (algoritmo) }\end{array}$ & $\begin{array}{l}\text { "(..) uma pessoa, } \\
\text { sabendo fazer uma } \\
\text { primeira vez, faz a } \\
\text { segunda, a terceira (...)" }\end{array}$ \\
\hline P5. Interagindo & $\begin{array}{l}\text { Versão a): aprende-se } \\
\text { através da interacção com } \\
\text { o computador }\end{array}$ & $\begin{array}{l}\text { "(..) para aprender tem } \\
\text { que haver interactivida- } \\
\text { de entre sujeito e o } \\
\text { computador." }\end{array}$ \\
\hline
\end{tabular}




\begin{tabular}{|c|c|c|}
\hline & $\begin{array}{l}\text { Versão b): aprende-se } \\
\text { com o computador através } \\
\text { da interacção entre pares }\end{array}$ & $\begin{array}{l}\text { "(...) em grupo, se há } \\
\text { uma dúvida pode ser } \\
\text { que o outro não a tem e } \\
\text { que nos explique ou } \\
\text { vice versa" }\end{array}$ \\
\hline & $\begin{array}{l}\text { Versão c): aprende-se } \\
\text { com o computador através } \\
\text { da interacção professor e } \\
\text { aluno }\end{array}$ & $\begin{array}{l}\text { "(...) pode aprender } \\
\text { numa interacção profes- } \\
\text { sor e aluno." }\end{array}$ \\
\hline P6. Compreendendo & $\begin{array}{l}\text { Aprende-se com o com- } \\
\text { putador relacionando um } \\
\text { conceito existente com } \\
\text { outras informações }\end{array}$ & $\begin{array}{l}\text { "(...) é dar um salto } \\
\text { novo, tendo por base } \\
\text { um conceito que nós já } \\
\text { temos" }\end{array}$ \\
\hline \multirow[t]{2}{*}{ P7. Modificando-se } & $\begin{array}{l}\text { Versão a): aprende-se } \\
\text { com o computador através } \\
\text { da percepção de si próprio } \\
\text { como capaz de aprender }\end{array}$ & $\begin{array}{l}\text { "(...) se somos nós que } \\
\text { vamos fazer buscas, } \\
\text { esses conhecimentos } \\
\text { novos...dessas lacunas } \\
\text { que nós sentimos, des- } \\
\text { sas falhas que nós sen- } \\
\text { timos, nós vamos utili- } \\
\text { zar o instrumento para ir } \\
\text { à procura desses sabe- } \\
\text { res, desses conceitos } \\
\text { novos." }\end{array}$ \\
\hline & $\begin{array}{l}\text { Versão b): aprende-se } \\
\text { com o computador através } \\
\text { de um processo de moti- } \\
\text { vação pessoal }\end{array}$ & $\begin{array}{l}\text { " }(\ldots) \text { desde que seja ela } \\
\text { própria a querer utilizar } \\
\text { o computador para isso, } \\
\text { acho que faz sempre } \\
\text { uma aprendizagem." }\end{array}$ \\
\hline
\end{tabular}

Dimensão Contextual - Onde se aprende com o computador

No que toca a esta dimensão é de referir a replicação das concepções de aprendizagem em geral, normalmente identificadas pela investigação fenomenográfica. Assim, a aprendizagem com o computador é tida quer num sentido mais restrito, como ocorrendo em contextos específicos da vida pessoal (i.e. habitação pessoal, contexto profissional) ou do meio educacional, quer, num sentido mais amplo, como ocorrendo no contexto alargado do ambiente.

O sistema de descrição das concepções de aprendizagem com o computador na dimensão contextual pode ser consultado na Tabela 5 . 
Tabela 5: Dimensão contextual (C) - "Onde se aprende com o computador"

\begin{tabular}{|c|c|c|}
\hline Concepção & Definição & Resposta ilustrativa \\
\hline \multirow[t]{2}{*}{ C1. Na vida pessoal } & $\begin{array}{l}\text { Versão a): a aprendi- } \\
\text { zagem com o compu- } \\
\text { tador realiza-se no } \\
\text { contexto da habitação } \\
\text { pessoal }\end{array}$ & $\begin{array}{l}\text { "Aprender (com o } \\
\text { computador) as pes- } \\
\text { soas aprendem em } \\
\text { casa." }\end{array}$ \\
\hline & $\begin{array}{l}\text { Versão b): a aprendi- } \\
\text { zagem com o compu- } \\
\text { tador realiza-se no } \\
\text { contexto da vida pro- } \\
\text { fissional }\end{array}$ & $\begin{array}{l}\text { "(...) pode ser no } \\
\text { emprego, agora prati- } \\
\text { camente todos os } \\
\text { empregos têm ligação } \\
\text { à Internet." }\end{array}$ \\
\hline \multirow[t]{2}{*}{ C2. No contexto educacional } & $\begin{array}{l}\text { Versão a): a aprendi- } \\
\text { zagem com o compu- } \\
\text { tador realiza-se no } \\
\text { contexto da escola }\end{array}$ & $\begin{array}{l}\text { " }(. . .) \text { as escolas agora, } \\
\text { quase todas têm, pode- } \\
\text { riam ter mais, mas } \\
\text { quase todas tem alguns } \\
\text { computadores, as } \\
\text { crianças podem apren- } \\
\text { der na escola." }\end{array}$ \\
\hline & $\begin{array}{l}\text { Versão b): a aprendi- } \\
\text { zagem com o compu- } \\
\text { tador realiza-se no } \\
\text { contexto académico }\end{array}$ & $\begin{array}{l}\text { "Em qualquer contex- } \\
\text { to na faculdade apren- } \\
\text { de-se." }\end{array}$ \\
\hline C3. No mundo & $\begin{array}{l}\text { A aprendizagem com o } \\
\text { computador realiza-se } \\
\text { no contexto alargado } \\
\text { do ambiente (i.e. } \\
\text { aprende-se em qual- } \\
\text { quer lugar e em qual- } \\
\text { quer momento) }\end{array}$ & $\begin{array}{l}(. . .) \text { acham um ciber- } \\
\text {-café, e tentam apren- } \\
\text { der como é que aquilo } \\
\text { funciona." }\end{array}$ \\
\hline
\end{tabular}

No que toca à dimensão funcional (i.e. a noção de para que se aprende com o computador) registou-se, próximas de uma concepção quantitativa, um tipo de respostas que traduzem uma noção de que a função da aprendizagem com o computador é a aquisição de informação.

Um outro tipo de respostas, mais diversificado, aproxima-se de uma concepção mais qualitativa, ao apontar como funções da aprendizagem com o computador: a diversificação do modo de aprendizagem; a facilitação da aprendizagem pela comunicação; a transferência de aprendizagens; a facilitação ou desenvolvimento de competências de aprendizagem (i.e. cognitivas 
e de produção do discurso); a construção de conhecimento; a autonomia; e a motivação para a aprendizagem.

Finalmente, verificou-se a emergência de um tipo de respostas mais próximas de uma concepção organizacional de aprendizagem, que associam a função da aprendizagem com o computador com um aumento de eficiência por parte do aprendente. São respostas que defendem que aprender com o computador tem a função de: aumentar a acessibilidade à informação; trazer uma maior comodidade na utilização da informação; rentabilizar o tempo de aprendizagem; possibilitar o transporte e um acesso contínuo à informação; ou poder aprender sem uma fonte presencial de informação ou à "distância". O sistema de descrição das concepções de aprendizagem com o computador na dimensão funcional pode ser consultado na Tabela 6 .

Tabela 6: Dimensão funcional (F) - "Para que se aprende com o computador"

\begin{tabular}{lll}
\hline Concepção & Definição & Resposta ilustrativa
\end{tabular}

\begin{tabular}{|c|c|c|}
\hline F1. Aquisição de informação & $\begin{array}{l}\text { A aprendizagem com o } \\
\text { computador permite } \\
\text { adquirir mais conheci- } \\
\text { mentos }\end{array}$ & $\begin{array}{l}\text { "(...) o computador } \\
\text { dá-nos muita informa- } \\
\text { ção" }\end{array}$ \\
\hline $\begin{array}{l}\text { F2. Acessibilidade de infor- } \\
\text { mação }\end{array}$ & $\begin{array}{l}\text { A aprendizagem com o } \\
\text { computador permite } \\
\text { aumentar a acessibilida- } \\
\text { de da informação }\end{array}$ & $\begin{array}{l}\text { "(...) não precisamos } \\
\text { de sair de casa, pode } \\
\text { ser de noite ou de dia, } \\
\text { estar a chover ou estar } \\
\text { sol, estamos em casa a } \\
\text { pesquisar informa- } \\
\text { ções.” }\end{array}$ \\
\hline $\begin{array}{l}\text { F3. Comodidade na utilização } \\
\text { de informação }\end{array}$ & $\begin{array}{l}\text { A aprendizagem com o } \\
\text { computador permite } \\
\text { aumentar a comodidade } \\
\text { na utilização de informa- } \\
\text { ção }\end{array}$ & $\begin{array}{l}\text { “(...) o computador } \\
\text { através da Internet, já é } \\
\text { possível fazer cópia e } \\
\text { passar e ajeitar, e é } \\
\text { muito mais cómodo." }\end{array}$ \\
\hline F4. Rentabilização do tempo & $\begin{array}{l}\text { A aprendizagem com o } \\
\text { computador permite } \\
\text { rentabilizar o tempo de } \\
\text { aprendizagem }\end{array}$ & $\begin{array}{l}(\ldots) \text { através da Inter- } \\
\text { net conseguimos tirar } \\
\text { tudo o que nós quere- } \\
\text { mos, mas sem estarmos } \\
\text { a perder, perdemos } \\
\text { muito menos tempo." }\end{array}$ \\
\hline $\begin{array}{l}\text { F5. Portabilidade da informa- } \\
\text { ção }\end{array}$ & $\begin{array}{l}\text { A aprendizagem com o } \\
\text { computador permite o } \\
\text { transporte e o acesso } \\
\text { contínuo da informação }\end{array}$ & $\begin{array}{l}\text { "(...) por ser um alia- } \\
\text { do nosso, um portátil } \\
\text { (...) vai sempre a } \\
\text { informação connosco, } \\
\text { acho que sim, apren- } \\
\text { demos muito." }\end{array}$ \\
\hline
\end{tabular}




\begin{tabular}{|c|c|c|}
\hline $\begin{array}{l}\text { F6. Diversificação do modo } \\
\text { de aprendizagem }\end{array}$ & $\begin{array}{l}\text { A aprendizagem com o } \\
\text { computador permite } \\
\text { diversificar o modo de } \\
\text { aprendizagem }\end{array}$ & $\begin{array}{l}\text { "(...) é importante, } \\
\text { porque dá ao sujeito a } \\
\text { possibilidade de traba- } \\
\text { lhar com vários pro- } \\
\text { gramas de várias } \\
\text { maneiras, não aprender } \\
\text { só de forma tradicio- } \\
\text { nal." }\end{array}$ \\
\hline F7. Aprendizagem à distância & $\begin{array}{l}\text { A aprendizagem com o } \\
\text { computador permite } \\
\text { aprender sem estar na } \\
\text { presença da fonte de } \\
\text { informação }\end{array}$ & $\begin{array}{l}\text { "(...) há a universida- } \\
\text { de electrónica, há } \\
\text { aprendizagem à distân- } \\
\text { cia, há e-learning." }\end{array}$ \\
\hline $\begin{array}{l}\text { F8. Facilitação } \\
\text { da aprendizagem } \\
\text { pela comunicação }\end{array}$ & $\begin{array}{l}\text { A aprendizagem com o } \\
\text { computador facilita a } \\
\text { troca de informação } \\
\text { envolvida na aprendiza- } \\
\text { gem }\end{array}$ & $\begin{array}{l}\text { "(...) é uma troca de } \\
\text { informação, uma troca } \\
\text { de conhecimentos, } \\
\text { saber, experiências } \\
(\ldots) "\end{array}$ \\
\hline $\begin{array}{l}\text { F9.Transferência de aprendi- } \\
\text { zagens através do jogo }\end{array}$ & $\begin{array}{l}\text { A aprendizagem com o } \\
\text { computador como um } \\
\text { meio numa situação de } \\
\text { jogo, permite transferir } \\
\text { aprendizagens para a } \\
\text { vida }\end{array}$ & $\begin{array}{l}\text { “...) a jogar um jogo, } \\
\text { a jogar um jogo de } \\
\text { estratégia, estando em } \\
\text { contacto com a tecno- } \\
\text { logia, que também } \\
\text { poderei aprender } \\
\text { alguns aspectos que } \\
\text { serão posteriormente } \\
\text { utilizados no meu dia a } \\
\text { dia, em que, ainda } \\
\text { embora não tenhamos } \\
\text { consciência de que } \\
\text { estamos aprender, em } \\
\text { qualquer situação tam- } \\
\text { bém de jogo.” }\end{array}$ \\
\hline \multirow[t]{3}{*}{$\begin{array}{l}\text { F10. Facilitação } \\
\text { de competências } \\
\text { de aprendizagem }\end{array}$} & \multirow{2}{*}{$\begin{array}{l}\text { Versão a): a aprendiza- } \\
\text { gem com o computador } \\
\text { permite facilitar o desen- } \\
\text { volvimento } \\
\text { de competências cogniti- } \\
\text { vas (i.e. memorização; } \\
\text { raciocínio) }\end{array}$} & $\begin{array}{l}\text { "(...) facilita muito } \\
\text { também }(. . .) \text { a memo- } \\
\text { rização }(. .) "\end{array}$ \\
\hline & & $\begin{array}{l}\text { "(...) facilita pelo o } \\
\text { raciocínio nos jogos de } \\
\text { estratégia" }\end{array}$ \\
\hline & $\begin{array}{l}\text { Versão b): a aprendiza- } \\
\text { gem com o computador } \\
\text { permite facilitar compe- } \\
\text { tências de aprendizagem } \\
\text { como a escrita e apresen- } \\
\text { tação de trabalhos }\end{array}$ & $\begin{array}{l}\text { " (...) uma vez que a } \\
\text { pessoa escreve e depois } \\
\text { aparece lá, ou já identi- } \\
\text { fica os erros, muitas } \\
\text { vezes isso pode ajudar } \\
\text { com o aprender a }\end{array}$ \\
\hline
\end{tabular}


escrever."

\begin{tabular}{|c|c|c|}
\hline & & \multirow[b]{2}{*}{$\begin{array}{l}\text { " }(\ldots) \text { aprendemos }(. . .) \\
\text { a fazer textos, a fazer } \\
\text { slides para uma apre- } \\
\text { sentação }(. .) \text { a cons- } \\
\text { truir trabalhos de } \\
\text { maneira mais apresen- } \\
\text { tável }(. . .) . "\end{array}$} \\
\hline & & \\
\hline $\begin{array}{l}\text { F11. Construção do conheci- } \\
\text { mento }\end{array}$ & $\begin{array}{l}\text { A aprendizagem com o } \\
\text { computador permite } \\
\text { construir novos conhe- } \\
\text { cimentos }\end{array}$ & $\begin{array}{l}\text { "(...) trabalhar com o } \\
\text { computador é algo das } \\
\text { nossas aprendizagens } \\
\text { que nós temos anterio- } \\
\text { res }(. . .) \text { serve para } \\
\text { construir esse mundo } \\
\text { interior de conhecimen- } \\
\text { tos de categorização, de } \\
\text { execução de cálculo, a } \\
\text { nível gráfico." }\end{array}$ \\
\hline F12. Autonomia & $\begin{array}{l}\text { A aprendizagem com o } \\
\text { computador permite } \\
\text { desenvolver a autonomia }\end{array}$ & $\begin{array}{l}\text { "(...) como somos nós } \\
\text { que temos o contacto } \\
\text { directo com o compu- } \\
\text { tador, poderá desen- } \\
\text { volver } \\
\text { uma componente mais } \\
\text { de autonomia, de nós } \\
\text { irmos à procura, de nós } \\
\text { sermos capazes se } \\
\text { temos alguma dificul- } \\
\text { dade, nós sermos capa- } \\
\text { zes de ir buscar infor- } \\
\text { mação nova." }\end{array}$ \\
\hline F13. Motivação & $\begin{array}{l}\text { A aprendizagem com o } \\
\text { computador permite uma } \\
\text { motivação para as apren- } \\
\text { dizagens }\end{array}$ & $\begin{array}{l}\text { " }(\ldots) \text { vai criar nas } \\
\text { pessoas uma espécie de } \\
\text { incentivo, mais curio- } \\
\text { sidade, mais estímulo- } \\
\text {-resposta, faço isso, } \\
\text { recebo isto." }\end{array}$ \\
\hline
\end{tabular}

Em suma, os resultados deste estudo permitem-nos concluir que a aprendizagem com o computador pode ser principalmente representada pelos estudantes quer em termos de uma concepção quantitativa (i.e. como meio 
de aquisição, manipulação e aplicação de informação), quer em termos de uma concepção qualitativa (i.e. como apoio no processo de compreensão de conhecimentos), quer em termos de uma concepção institucional (i.e. como meio de obter classificações), quer, por fim, em termos de uma concepção organizativa (i.e. como forma de aumentar a eficiência e organizar a informação).

\section{Discussão}

Pela análise dos resultados é possível constatar uma marcada correspondência entre as concepções de aprendizagem com o computador identificadas e as concepções de aprendizagem em geral, normalmente pontuadas pela investigação fenomenográfica. Tal facto poderá ser explicado pela hipotética dependência das primeiras, mais específicas, em relação às segundas, mais nucleares. No entanto, emergiram concepções novas, não previstas teoricamente, que se podem explicar pela noção dos constrangimentos e potencialidades particulares que a utilização do computador cria na aprendizagem.

Ao nível da dimensão referencial confirma-se a correspondência de várias das concepções de aprendizagem com o computador com concepções de aprendizagem em geral (Marton et al. 1993; Säljö, 1979, citado por Marton et al., 1993). Observa-se assim, tal como nestes estudos, que inquerem sobre a concepção de aprendizagem em geral, noções de que a aprendizagem (neste caso com o computador) constitui por um lado "aquisição de informação" ou sua "memorização" ou, por outro, sua "compreensão". Talvez esta antinomia, bem ilustrada na investigação fenomenográfica anterior, traduza a consciência do computador quer como um auxiliar da aquisição mais passiva de informação (e.g. a utilização da Internet para copiar-colar conteúdos) quer como um facilitador de uma aprendizagem activa (e.g. a utilização da Internet para navegar entre conteúdos relacionados). De igual modo, é de salientar a replicação neste contexto, da concepção "institucional”, sugerida por Biggs e Moore (1993) e que aqui apresenta a aprendizagem com o computador como processo de obtenção de classificações. Complementarmente, emergiu uma concepção sem correspondente com as concepções de aprendizagem em geral, que toma a aprendizagem com o computador por "repetição de procedimentos". Talvez esta concepção derive da consciência de que muitas aplicações informáticas facilitam/impõem a aplicação de algoritmos. Emergiu também, uma concepção da aprendizagem com o computador como "manipulação de informação", parecendo reflectir a consciência do computador como potencial auxiliar para a organização do conhecimento (e.g. a utilização de uma base de dados para categorizar conteúdos). 
No que diz respeito à dimensão processual, observou-se a replicação neste contexto de uma concepção quantitativa, mas sobretudo através de noções sem correspondente directo com as que tipicamente a representam: aprende-se com o computador imitando, praticando e automatizando. Isto pode significar a consciência de que a utilização do computador é dependente do domínio de algoritmos ou procedimentos rotineiros, a que a utilização de uma máquina sempre obriga, em maior ou menor grau.

Ainda no que toca à dimensão processual, refira-se a replicação da concepção qualitativa, patenteada em ideias já conhecidas de que a aprendizagem passa pela compreensão e pela mudança. Mas também na noção de que aprender com o computador, e isto é novo, constitui um processo interactivo. Esta ideia pode talvez ser explicada pela consciência do computador como um sistema tão complexo que se oferece como um interlocutor ou que exige do aprendente a colaboração social com outros indivíduos, no processo de o utilizar como meio de aprendizagem. Esta noção pode ainda radicar na consciência de que grandes partes das aplicações informáticas são interactivas ou de que a aprendizagem pode ser um processo colaborativo.

No que toca à dimensão contextual constata-se a replicação das concepções normalmente identificadas pela investigação fenomenográfica. Assim, regista-se quer a noção de que a aprendizagem com o computador se realiza em ambientes específicos (e.g. casa, emprego, escola), o que poderá reflectir uma perspectiva mais instrumental daquele recurso, quer a noção de que a aprendizagem com o computador pode ocorrer em qualquer contexto, o que poderá associar-se a uma perspectiva desta como um processo mais compreensivo.

Considerando a dimensão funcional, as principais concepções parecem traduzir um isomorfismo com a concepção quantitativa e qualitativa das dimensões anteriores: aprende-se com o computador para adquirir passivamente informação ou, em alternativa, para uma apropriação activa de conhecimento. Já a terceira concepção emergente, que vê a função da aprendizagem com o computador em termos da rentabilização e organização do próprio processo de aprendizagem, pode ser explicada pelo potencial de gestão, rapidez de processamento e organização de informação dos actuais meios informáticos.

Os resultados contribuem para a consolidação da perspectiva fenomenográfica, que tem investigado as concepções que os indivíduos têm sobre a aprendizagem, na medida em que apontam para uma replicação das três principais concepções de aprendizagem em geral (i.e. quantitativa, qualitativa e institucional) na concepção de aprendizagem com o computador. Por outro lado, os resultados contribuem para a extensão daquela mesma perspectiva ao desvendarem novas concepções de aprendizagem (i.e. organizativa) e um leque de variantes das concepções principais. Considerando a 
escassez dos estudos sobre a representação dos estudantes sobre a aprendizagem com o computador os resultados têm uma implicação no conhecimento sobre esse fenómeno, corroborando e expandindo resultados de estudos anteriores (i.e. van den Brink et al., 2000).

A variação de concepções encontrada vai no sentido da análise de van den Brink e colaboradores (2000) de que o computador pode ser representado pelos estudantes como um recurso de actualização de uma concepção de aprendizagem previamente estruturada. Ou seja, um recurso que tanto pode facilitar uma mera aquisição de informação, aumentando a eficiência de uma aprendizagem de "superfície", como pode promover a capacidade de reflectir e de questionar, potenciando uma aprendizagem mais de "profundidade". Recorrendo a duas metáforas, esta variação sugere uma representação do computador quer como "mais lenha para a mesma fogueira", no sentido de um recurso organizado que pode rentabilizar uma aprendizagem mais passiva, quer como um "cavalo de Tróia", no sentido de um recurso que encerra o potencial para uma aprendizagem mais activa. Neste sentido, o presente estudo confirma os resultados deste estudo anterior e expande-os ao mapear mais extensivamente as variantes das três concepções básicas de aprendizagem com o computador. Em estudos futuros seria interessante investigar igualmente a forma como os estudantes justificam as suas concepções de aprendizagem com o computador.

Finalmente, os resultados têm possíveis implicações para a aprendizagem, considerando que as concepções de aprendizagem com o computador são provavelmente um factor da forma como efectivamente se aprende com o computador. Assim, se pretendemos que a aprendizagem que os estudantes processam com o computador constitua um processo realmente activo, baseado na compreensão e na construção pessoal de significados, provavelmente não basta disponibilizar aquele recurso e esperar que, pelo seu potencial, ele facilite automaticamente aquela aprendizagem. Para que isso aconteça importa então avaliar e eventualmente intervir no tipo de concepções que os estudantes têm sobre a aprendizagem com o computador. Possivelmente, esta intervenção poderá compreender procedimentos que possibilitem uma consciência metacognitiva sobre as concepções pessoais, o conhecimento de concepções alternativas e a eventual reestruturação das concepções pessoais. O conhecimento pelos professores e psicólogos escolares destas concepções de aprendizagem com o computador poderá ajudá-los a compreenderem melhor os estudantes e assim adequarem as suas intervenções educacionais e psico-educacionais nesta área (e.g. adequar o estilo de ensino à concepção de aprendizagem para depois eventualmente altera-lo de forma a alterar essa concepção). O conhecimento pelos estudantes e professores das variantes da dimensão funcional das concepções de aprendizagem com o computador poderá ainda ajudar a diversificar o modo como ambos os gru- 
pos utilizam o computador como meio de aprendizagem. Essa intervenção, coadjuvada com outra nas abordagens que os estudantes utilizam no estudo, poderá constituir um importante factor de uma aprendizagem efectivamente activa e profunda com o computador.

\section{Referências}

Bakeman, R. \& Gottman, J. (1986). Observing interaction: An introduction to sequential analysis. London: Cambridge University Press.

Biggs, J. B., \& Moore, P. J. (1993). The process of learning (3rd.Ed.). N.Y.: Prentice Hall.

Boulton-Lewis, G. M., Wilss, L., \& Lewis, D. C. (2001). Changes in conceptions of learning for Indigenous Australian university students. British Journal of Education, Psychology, 71, 327-341.

Bowden, J. \& Marton, F. (2004). The university of learning. Routledge Falmer.

Cliff, A. F. (1998) Teacher-learners' conceptions of learning: Evidence of a "communalist" conception amongst postgraduate learners? Higher Education, 35(2), 205-220.

Dias, P. (2000). Hipertexto, hipermédia e media do conhecimento: representação distribuída e aprendizagens flexíveis e colaborativas na Web. Revista Portuguesa de Educação, 13 (1), 141-167.

Duarte, A. (2000). Psycho-educational evaluation \& design of multimedia: some guidelines based on the "approaches to learning" perspective. $X$ Colóquio AFIRSE Portuguesa (770-782). Faculdade de Psicologia e de Ciências da Educação - Universidade de Lisboa.

Duarte, A. M. (2007). Conceptions of learning and approaches to learning in Portuguese students. Higher Education. 54, 781-794.

Duarte, A. M. (2008). E-learning e abordagens à aprendizagem no Ensino Superior / E-learning and approaches to learning in higher education. Sisifo, 7, 39-50.

Edmunds, R. \& Richardson, J. T. E. (2009). Conceptions of learning, approaches to studying and personal development in UK higher education. British Journal of Educational Psychology, 79, 295-309

Eklund-Myrskog, G. (1998). Students` conceptions of learning in different educational contexts. Higher Education, 35, 299-316

Entwistle, N. J. \& Peterson, E. R. (2004). Conceptions of learning and knowledge in higher education: Relationships with study behavior and influences of learning environments. International Journal of Educational Research, 41, 407-428

Flores, J. G. (1994). Análisis de datos cualitativos: Aplicaciones a la investigación educativa. Barcelona: PPV

Gerjets, P. H. \& Hesse, F. W. (2004). When are powerful learning environments effective? The role of learner activities and of students' conceptions of educational technology. International Journal of Educational Research, 41, 445-465

Hounsell, D. (1984). Learning and essay writing. In F. Marton, D. Hounsell \& N. 
Entwistle (Eds.), The experience of learning, 106-125. Edinburgh: The Scottish Academic Press.

Jonassen, D. (1996). Computers in the classroom: Mindtools for critical thinking. Columbus, OH: Merrill/Prentice Hall.

Kirby, J. R., Knapper, C. K., Maki, S. A., Egnatoff, W. J. \& vanMelle, E. (2002). Computers and students' conceptions of learning: the transition from post-secondary education to the workplace. Educational Technology \& Society, 5 (2), 47-53

Laurillard, D. (1994). How can learning technologies improve learning. Law Technology Journal, l3, 2. Consultado a 2-11-2004 em htpp://www.law.warwick. ac.uk/Itj/3-2j.html

Marton, F. (1981). Phenomenography - Describing conceptions of the world around us. Instructional Science, 10, 177-200

Marton, F. (1986). Phenomenography - A research approach to investigating different understandings of reality. Journal of Thought, 21 (3), 28-49

Marton, F., \& Booth, S. (1997). Learning and awareness. Mahwah: Lawrence Erlbaum

Marton, F., Dall Alba, G., \& Beaty, E. (1993). Conceptions of learning. International Journal of Educational Research, 19 (3), 277-300

Mavers, D., Somekh, B., \& Restorick, J. (2002). Interpreting the externalised images of pupils' conceptions of ICT: Methods for analysis of concept maps. Computers \& Education, 38, 187-207

Miles, M. B., \& Huberman, A. M. (1994). Qualitative data analysis: An expanded sourcebook (2nd. Ed.). Thousand Oaks, California: Sage Publications

Säljö, R. (1982). Learning and understanding: A study of differences in constructing meaning from a text. Göteborg: Acta Universitatis Gothoburgensis

Säljö, R. (1984). Learning from reading. In F.Marton, D.Hounsell, N.Entwistle (Eds.) The experience of learning, 89-105. Edinburgh: The Scottish Academic Press.

Säljö, R. (1994). Minding action. Conceiving of the world versus participating in cultural practices. Nordisk Pedagogik, 2, 71-80

Shuell, T. J. \& Farber, S. L. (2001). Students' perceptions of technology use in college courses. Journal of Educational Computing Research, 24, 119-138

Rendeiro, A. I. \& Duarte, A. M. (2007). Concepções de aprendizagem face à avaliação em estudantes do ensino secundário. In A. M. Veiga Simão, A. Lopes da Silva \& I. Sá (Orgs.) Auto-Regulação da Aprendizagem. Das concepções às práticas, 63-92. Lisboa: Ui\&dCE \& Educa

van Den Brink, K., Alemany, I., Plat, A., Duarte, A., Ericsson, L., \& Slack, R. (2000). Student's learning with educational multimedia in school - A multinational study. Colóquio AFIRSE Portuguesa (723-740). Lisboa: Faculdade de Psicologia e de Ciências da Educação - Universidade de Lisboa.

Van Rossum, E.J. e Schenk, S. (1984). The relationship between learning conception, learning strategy and learning outcome. British Journal of Educational Psychology, 54, 73-83.

Zhang, Z. \& Huang, R. (2006). Why do students engage in e-learning: A Chinese perspective. Proceedings of the 14th International Conference on Computers in Education, 423-441. IOS Press. 